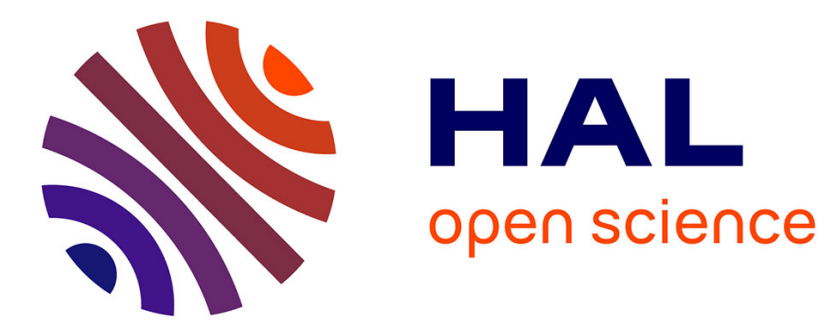

\title{
Exploring the link between stigma and social representations among people with and without schizophrenia in the French context
}

Dimitrios Lampropoulos, David Fonte, Thémis Apostolidis

\section{- To cite this version:}

Dimitrios Lampropoulos, David Fonte, Thémis Apostolidis. Exploring the link between stigma and social representations among people with and without schizophrenia in the French context. Psychiatry Research, 2019, 272, pp.595-601. halshs-01977603

\section{HAL Id: halshs-01977603 \\ https://shs.hal.science/halshs-01977603}

Submitted on 13 Oct 2021

HAL is a multi-disciplinary open access archive for the deposit and dissemination of scientific research documents, whether they are published or not. The documents may come from teaching and research institutions in France or abroad, or from public or private research centers.
L'archive ouverte pluridisciplinaire HAL, est destinée au dépôt et à la diffusion de documents scientifiques de niveau recherche, publiés ou non, émanant des établissements d'enseignement et de recherche français ou étrangers, des laboratoires publics ou privés. 
Title:

Exploring the link between stigma and social representations among people with and without schizophrenia in the French context

Dimitrios Lampropoulos ${ }^{\mathrm{a}^{*}}$, David Fonte ${ }^{\mathrm{a}}, \&$ Thémis Apostolidis ${ }^{\mathrm{a}}$

a Aix Marseille Univ, LPS, Aix en Provence, France

* Correspondence concerning this manuscript should be addressed to Dimitrios

Lampropoulos, Laboratoire de Psychologie Sociale, Aix-Marseille Université, 29 avenue

Robert Schuman, 13621 Aix-en-Provence, France. Telephone: +33640771386

Email: dimilamprop@gmail.com 


\section{Introduction}

The stigma of schizophrenia is an important issue in the fields of socio-political rights and public health, having negative consequences for the lives of people with schizophrenia. This stigmatization is likely to have an impact on their ability to act autonomously (Corrigan, 1998), their social and professional integration (Rebeiro Gruhl et al., 2012), their ways of seeking care and the development of the disorder (Fung et al., 2008; Mak et al., 2007) as well as their mortality risk (Acosta et al., 2013). Consequently, the World Health Organization has launched a fight against stigma as one of the priorities in mental health policies and services (WHO, 2013, 2003).

Stigma is associated with norms, stereotypes and practices that are related to a cultural context. One of the principal dimensions of stigma is the association of negative images with a labeled condition or physical mark (Link and Phelan, 2013). The social imaginary in relation to schizophrenia leads to perceived or experienced stigma by people with schizophrenia or even to self-stigma, where the stigmatized individuals know the stereotypes associated with this disorder, agree with them and apply them to themselves (Corrigan et al., 2005). Research drawn from Link's works on Perceived Devaluation and Discrimination has shown the negative consequences of the perception of social stigma (Link, 1987; Link et al., 1987; Link and Phelan, 2013) and that higher levels of social stigma are associated with higher perceived stigma or self-stigma among people living with a mental disorder (EvansLacko et al., 2012).

This social imaginary is created and reproduced inside "a dominant culture". The relationship between culture and stigma manifestations has been frequently suggested (Angermeyer et al., 2016; Yang et al., 2007). For instance, cultural background is a factor related to different levels of perception of dangerousness of people with schizophrenia 
(Abdullah and Brown, 2011). Moreover, the association with "split personality", which often refers to the idea of unpredictability and unreliability (Duckworth et al., 2003), is not found in all studied cultures (Schomerus et al., 2007).

France is an interesting cultural context for the study of the stigma of schizophrenia, in which the social and professional integration of people with this disorder has rather recently been established as a real mental health priority by the government (Ministère du travail, de l'emploi et de la santé, 2011). It is important to underline that in France, research into mental illness stigma has not developed as significantly as it has in other western countries (Lampropoulos et al., 2018). Moreover, the few existing works on the public's perceptions of schizophrenia employ quantitative methodologies and internationally-established questionnaires (Angermeyer et al., 2013; Durand-Zaleski et al., 2012) while qualitative works exploring the impact of culture on the stigma of schizophrenia are rather absent. An analysis of the French press has shown that the word "schizophrenia" was used in a stigmatizing fashion in the vast majority of the analyzed articles and was associated with the ideas of dangerousness and split personality (Lampropoulos et al., 2017). It also suggested that the clear lack of positive or even non-stigmatizing depictions of schizophrenia by the French press is symptomatic of the existence of a shared, consensual, negative image of schizophrenia in the French context.

The social representations approach (Farr and Moscovici, 1984) offers a heuristic framework for studying the social imaginary which individuals draw on when considering schizophrenia from their cultural context of reference. Social representations can be defined as a kind of knowledge that is socially developed and shared, having a practical aim and contributing to the construction of a reality that is common to a social group (Jodelet, 2003). Applied to the stigma phenomenon, this approach is based on the idea that representations associated with social stigma are constructed in systems of meanings and communication 
dynamics based on our social belongings and social participations. Thus, in line with Link's works on perceived devaluation and discrimination, this approach allows us to contextualize stigmatizing opinions concerning schizophrenia.

Moreover, this approach also allows us to work on negative opinions that individuals are likely to not express themselves publicly about stigmatized groups such as people with schizophrenia. Specifically, a technique called "substitution" was proposed in order to manipulate the contexts of individuals' expression and thus circumvent their self-censorship attitude towards their own stigmatizing opinions (e.g. (Flament and Milland, 2010). This technique consists of asking people to express their personal opinion about stigmatized groups and more generally, about sensitive, normative objects in two different contexts; firstly, in their own name and then in the name of their group of belonging. Thus, this second step, called the substitution instruction aims to reduce participants' personal involvement and alleviate the social pressure they may feel, by asking them to answer as "others" that share the same social context and group of belonging would (e.g. French people in general). This allows them to express negative opinions about a stigmatized group, as was the case in previous research concerning the group of gypsies (Guimelli and Deschamps, 2000). In other words, we can expect participants answering in their own name to tend to produce less stigmatizing and stereotypical answers, while attributing more negative stereotypes to "others". This difference between the opinions that individuals express on their own behalf and those they express when they answer in the name of significant groups indicates that the stigmatized group benefits from "normative protection" (Guimelli et al., 2010) - that is, the public expression of negative opinions against this group is considered as socially unacceptable.

Despite its value in exposing stigmatizing opinions that may be masked in typical selfreported instructions in surveys, a substitution instruction has never been used to specifically 
study the representations associated with the stigma of schizophrenia. However, the comparison between the representations that people without schizophrenia draw on when thinking about schizophrenia (i.e., standard instruction) with the ones they draw on when they imagine themselves in the place of members from their groups of belonging (i.e., substitution instruction) is an important issue in identifying the actual level of stigmatization, as well as the extent to which this group benefits from normative protection. Concerning people with schizophrenia, this comparison between standard instructions and substitution instructions would allow us to better understand the relationship between their perception of stigmatizing opinions maintained within their groups of belonging and self-stigma that may result from internalization of these opinions.

Thus, based on the lack of contextualized research in the French context and drawing on the social representations approach, the present research aims to:

- Explore the cognitive content that individuals with and without schizophrenia spontaneously associate with the object "schizophrenia" in a contextualized way;

- Compare the content that people in both categories draw on when they express themselves on their own behalf and when they imagine how French people in general express themselves on this matter;

- Determine whether people with schizophrenia benefit from a normative protection that does not allow the direct expression of stigmatizing words. This last point allows us to go beyond the exploration of the Perceived Devaluation and Discrimination against schizophrenia by participants without schizophrenia.

\section{Methods}

\subsection{Participants and procedure}


This exploratory research was carried out in France, among people with and without schizophrenia. Due to the difficulty of accessing a population of people with schizophrenia, we conducted an online study by recruiting our participants via the Facebook social network. This recruitment strategy is seen as effective in building a sample from a rare or very specific population (Reips, 2002). We posted a recruitment advertisement in two support groups for Francophones with schizophrenia ( $N=1500$ registered members). In this announcement, the investigator presented himself as a human science researcher. He invited group members to take part in a study of their opinions about schizophrenia. Volunteers could not access the online questionnaire before giving full informed consent. Recruitment was completed when there was no new participant for several consecutive days.

Recruitment of participants without schizophrenia was done randomly in several public places in the south of France, such as university libraries, train and bus stations, and busy streets. We followed a paired sample recruiting procedure, the aim of which was to match the characteristics of the sample of people with schizophrenia, in terms of sex, age and education level. The research was presented to them as a survey of French people's opinions of schizophrenia. Volunteers were informed that the survey questionnaire was anonymous and confidential, and that they were free to withdraw from the survey at any time. The questionnaire was given to participants only after they had given their consent. All participants reported that they had never been diagnosed with schizophrenia. The AixMarseille University Ethics Committee approved the study procedure.

\subsection{Measures}


Data were collected through self-administered questionnaires. In order to highlight the cognitive content associated with schizophrenia, we used the verbal association technique, traditionally used in the study of social representations (Dany et al., 2015; Lo Monaco et al., 2017), but also in previous research on schizophrenia stigma (Schomerus et al., 2007). Participants were asked to produce five words spontaneously based on the inductor word "schizophrenia". In order to identify the representations that the participants attribute to other people in the French national context, they were asked to respond a second time to the technique of verbal association. From the work done on the "substitution instruction" in the social representations approach (Flament et al., 2006; Guimelli and Deschamps, 2000), participants were invited to respond not on their own behalf but rather "as the French in general would". It should be noted that the order of the two instructions was counterbalanced. The questionnaire ended with the information on socio-demographic characteristics.

\subsection{Analyses}

The words and expressions produced by the verbal associations were categorized using lemmatization, following the rules of content analysis (Di Giacomo, 1980). Thus, the various forms of the same word were reduced to the most common form and the different words having the same meaning were also regrouped. With a view to researcher triangulation (Denzin, 2009), this categorization was carried out by two of the co-authors. If one of the authors did not agree with a categorization proposal, the word was the object of discussion until consensus was reached. At the end of this process, data were submitted to a prototypical analysis, with IRaMuTeQ ${ }^{1}$ software in order to explore the cognitive content produced by the verbal association technique. More precisely, this analysis indicates the salience of this

\footnotetext{
${ }^{1}$ A software developed by Pierre Ratinaud (http://www.iramuteq.org/).
} 
content, based on the intersection of two criteria: the frequency of appearance of a word and the mean rank of the order of appearance.

In order to explore the structure of internal organization of representations associated with schizophrenia, a similarity analysis (Flament, 1981; Maia et al., 2017) was performed using IRaMuTeQ. This analysis is based on the criterion of connexity that allows us to explore the force of a statistical relation between two representational elements that are produced by a verbal associations task (Lo Monaco et al., 2017). It is characterized by a graphical representation of relations of proximity that exist among words produced by verbal associations. These relations are evaluated on the basis of the Jaccard index (Jung and Pawlowski, 2014), which presents a statistical value between 0 (absence of relation) and 1 (strong relation). The software also allows to detect and visually show the "communities of words" on the basis of this index: words that are strongly related to each other are found within the same community and are distinguished from other communities of words with which they are weakly related. In our case, a similarity analysis allowed us to explore the relations between the representations that participants draw on when thinking about schizophrenia and those they project on to French people in general. This analysis was performed separately for participants with and without schizophrenia. Note that the graphical representations of the similarity analyses presented in the results come from the IRaMuTeQ software's statistical report.

\section{Results}

In total, 157 subjects (98 without and 59 with schizophrenia) agreed to participate in our study. Their characteristics are summarized in Table 1 . Besides occupation $\left(\chi^{2}=42.62\right.$, $\mathrm{df}=1$, $\mathrm{p}<0.001)$, the two samples had rather matching characteristics concerning sex, age and 
education level. Concerning participants with schizophrenia, the time since diagnosis was between two weeks and thirty-two years $(M=7.61$ years; $S D=8.70)$. Furthermore, 46 participants were receiving medical treatment at the time they filled in the questionnaire, while 13 were not taking any medication. Finally, 17 participants were in outpatient care, 26 were undergoing psychotherapy, 17 were recipients of social support and nine were not receiving any kind of mental health treatment at the time the research took place.

[INSERT TABLE 1 HERE]

\subsection{Exploration of cognitive content}

The prototypical analysis of verbal productions indicates the cognitive content that participants associate with schizophrenia (Table 1). When participants without schizophrenia answer on their own behalf, the participants thought of different labels, as well as words related to medical healthcare. Specific mental disorders such as "split personality" and "bipolar" were noted that are generally confused with schizophrenia. The word danger also appeared among the produced words, even though not so frequently as the previously mentioned words.

When participants without schizophrenia were asked to answer on behalf of "French people", their answers were somewhat similar to the ones they gave on their own behalf. We observe however that they often attributed to French people some negative answers that they did not mention when answering on their own behalf (e.g. "psychopath") or they emphasized more words already used in their own name (e.g. "madness" replaced "illness" as the most frequently produced association with schizophrenia). However, participants without schizophrenia associated the words "danger" (McNemar's $\left.\chi^{2}=1.47, \mathrm{df}=1, \mathrm{p}=0.22\right)$ and 
"split personality" (McNemar's $\chi^{2}=0.86, \mathrm{df}=1, \mathrm{p}=0.35$ ) with schizophrenia both when answering on their own behalf and on behalf of the French people in general.

Interestingly, participants with schizophrenia seemed quite aware of the way their disorder was perceived by participants without schizophrenia, while adding some new words, that have a particularly stigmatizing character (e.g., "killer", "abnormal"). The word "danger" also appeared more frequently for participants with schizophrenia answering on behalf of French people, compared to participants without schizophrenia, when they answered on their own behalf $\left(\chi^{2}=34.86, \mathrm{df}=1, \mathrm{p}<0.001\right)$ or on behalf of French people $\left(\chi^{2}=17.48, \mathrm{df}=1, \mathrm{p}\right.$ $<0.001)$. On the contrary, "split personality" was equally frequent when participants with schizophrenia answered on behalf of French people, both compared to participants without schizophrenia answering on their own behalf $\left(\chi^{2}=0.02, \mathrm{df}=1, \mathrm{p}=0.90\right)$, as well as on behalf of French people $\left(\chi^{2}=1.31, \mathrm{df}=1, \mathrm{p}=0.25\right)$.

Contrary to these results, participants with schizophrenia answering on their own behalf spoke of symptoms typical of schizophrenia and used words referring to their subjective experience, mainly related to psychological suffering and to the experience of social isolation. Furthermore, they did not confuse schizophrenia with other disorders and the words "danger" and "split personality" were not present in the responses given by people with schizophrenia on their own behalf. However, words relative to schizophrenia labels (e.g., "illness", "madness") were present among the produced words, even though less salient than in previous results.

\section{[INSERT TABLE 2 HERE]}

\subsection{Relations among cognitive content}


The similarity analysis of verbal productions showed the statistical relation between the cognitive content that participants associated with the object "schizophrenia", when answering on their own behalf, as well as on behalf of French people. Results concerning participants without schizophrenia are presented in Figure 1. Firstly, we observe a rather systematic relationship between the words produced by participants on their own behalf and the ones they attributed to French people (e.g., "bipolar", "madness", "illness", "split personality", "confinement”, "mental illness", "treatment”, "hospital”, "fear"). Schizophrenia labels such as "madness" and "illness" occupy an important part of this graph that presents some rather meaningful lexical universes. In the upper part, one can find the word "split personality", attached to the word "bipolar" which could be interpreted as an association between the two words, associated in turn with "madness". "Split personality" is also connected with "confinement", as well as "mental illness". In turn, "mental illness" is related to both "treatment" and "danger". Interestingly, this latter was associated with a vocabulary that could be both directly concerned with the perceived dangerousness of schizophrenia, such as "psychopath" and "fear", but one can also find as related to both "danger" and "fear" the words "hospital" and "care".

\section{[INSERT FIGURE 1 HERE]}

Results concerning participants with schizophrenia are presented in Figure 2. This graph that is also constituted around the word "madness", has a number of interesting features. First of all, we can see in the middle of this graph, words produced by people with schizophrenia on their own behalf that concern symptoms related to schizophrenia (e.g., "hallucination", "delirium", "voices"). Further, we see some rather autonomous lexical universes that are constituted by on the one hand some of the most negative stereotypes about schizophrenia and 
on the other hand, words describing negative feelings and experiences of people with schizophrenia. Thus, we find that when they speak of "fear", "killer", "marginal" and "split personality" on behalf of French people in general, they also refer to "loneliness" and "isolation" on their own behalf. Similarly, when they personally associate schizophrenia with "fear", they also attribute the association of schizophrenia with "confinement", "violence" and, interestingly, "hospital" and "psychiatry" to the French. Likewise, reference on their own behalf to "suffering" is accompanied with the attribution of stigmatizing words to the French, such as "danger", "dumb” and "abnormal”.

[INSERT FIGURE 2 HERE]

\section{Discussion}

Our research aimed to explore the representations associated with schizophrenia, both for people with and without schizophrenia. Results showed that the representations of participants without schizophrenia are associated with a vocabulary relative to schizophrenia as an illness and with stigmatizing stereotypes, such as madness, dangerousness and split personality when they speak on their own behalf. The stereotypical responses that participants without schizophrenia draw on personally are also similar with those they draw on when they imagine what other French people think about schizophrenia. Indeed, for both instructions, the words that emerged were qualitatively identical and two of the most salient stigmatizing stereotypes (i.e., dangerousness and split personality) had a similar frequency. In accordance with the literature on social representations, the absence of a difference between standard and substitution instructions suggests that people with schizophrenia would not benefit from normative protection (Guimelli et al., 2010). This means that participants without 
schizophrenia would not 'mask' negative opinions towards people with schizophrenia when answering in their own name, suggesting that stigmatizing opinions on schizophrenia are not counter-normative. Moreover, previous international research has shown that the public also endorses ideas and emotions relative to pity and empathy concerning the suffering of people with schizophrenia (Thonon and Larøi, 2017). However, reference to this was rather absent from the answers of participants without schizophrenia, which could be interpreted in terms of stigma and the lack of "social" recognition of this suffering.

This hypothesis of a lack of normative protection can be reinforced and legitimized by the structural stigma operated by certain French institutions, such as the media. Specifically, we can find a striking similarity with the images that are reproduced by the French press, through the use of the word "schizophrenia" which mainly refers to the ideas of split personality, dangerousness and criminality (Lampropoulos et al., 2017). These stereotypes that are sustained by structural stigmatization and fuel social stigmatization do not correspond to a more complex reality concerning the relationship between schizophrenia and violence. Indeed, a meta-analysis suggests that risks of violence in people with schizophrenia are mediated by substance abuse comorbidity and that these people with comorbidity present a similar risk to that of substance abuse without schizophrenia (Fazel et al., 2009). Other authors suggest instead that people with schizophrenia are more victims than perpetrators of violence (Choe et al., 2008).

However, the social representations approach invites us here to consider representations about schizophrenia through their social and symbolic function rather than evaluate them in the light of scientific knowledge (Marková, 2005). From this perspective, it would seem that participants without schizophrenia and those with the disorder draw on different meanings when they represent the symptoms of schizophrenia. The first ones rather have a stereotypical view of schizophrenia as split personality and speak of the healthcare of schizophrenia such as 
hospital care and treatment. On the contrary, participants with schizophrenia do not make reference to these ideas on their own behalf, but they attribute them (and rather correctly) to "French people in general". Interestingly though, the results show that most of these ideas are in immediate proximity with the ideas of danger and fear for participants without schizophrenia and with confinement and fear for participants with schizophrenia. Thus, one has to wonder whether in the case of participants without schizophrenia, hospital and treatment are words that have a rather "social" meaning, associated with social control. This relationship has also been suggested by the analysis of the French newspapers' presentation of people with schizophrenia (Lampropoulos et al., 2017). Specifically, schizophrenia as a disorder with its symptoms, risk factors and treatment is rather marginal in both the press and the verbal productions of our sample without schizophrenia. But in both cases, when treatment makes its appearance, it seems to be associated with questions of social control, rather than mental health promotion and literacy. These findings could show that representations relative to the psychiatric care of schizophrenia are in line with a series of studies that have suggested that cognitive content concerning schizophrenia that could be interpreted as knowledge of the disorder, such as attributing biogenetic causes or accurate labeling, is actually associated with stigmatizing attitudes (Lampropoulos and Apostolidis, 2018; Read et al., 2006).

Concerning participants with schizophrenia, they seem to have a clear view of the stereotypes of people without schizophrenia when they imagine how French people in general express themselves about schizophrenia. On the contrary, there is no reference to stigmatizing ideas when they have to express themselves on their own behalf about their mental disorder. However, results show a relationship between knowledge of the public's stereotypes and negative experiences and emotions such as loneliness, suffering and fear when they speak on their own behalf about schizophrenia. 
Besides, the striking similarity between the productions of people without schizophrenia and the ones given by people with schizophrenia answering on behalf of French people, suggests the existence of a consensus in the social world as to what schizophrenia is. As Goffman (Goffman, 1963) would suggest, work on stigma is not just the study of an attribute but mainly the study of relationships. Much research has focused on the attribute and its characteristics, while forgetting Goffman's idea that it is through social relationships and interactions inside pre-established frameworks that we learn, share, and co-construct social identities. These social identities become social anticipations, normative expectations shared by both the "normal" and the stigmatized. Hence, even though schizophrenia is not clinically related to "split personality", people suffering from it have to also suffer the social anticipations related to their association with "split personality", dangerousness and confinement. Our approach also highlights how crucial aspects of the stigma of schizophrenia, such as Link's concept of perceived discrimination-devaluation associated to labeling (Link et al., 1987) emerge through networks of meanings from which people with schizophrenia make sense of their relationship with mental disorders and others.

Two important limitations of our study need to be considered. The first is related to the specific profile of participants living with schizophrenia, who were recruited through Facebook groups. In these groups, one can find discussions about the disorder, both on a clinical level and concerning stigma and life difficulties. Therefore, we consider that active participation in these groups could be associated with higher insight into stigma, compared to people with schizophrenia that do not use such platforms. Given the important impact of stigma on their psychological and social well-being (Yanos et al., 2008), the protective effect of belonging to these online support groups against the risk of self-stigmatizing should be further explored in future research. The second limitation concerns the small number of participants, which does not allow the results to be generally applied to the entire population 
studied. However, in terms of transferability of data, our exploratory research can provide an interesting framework for the understanding of stigmatization in comparable populations and contexts.

Future research should further explore the representations associated with schizophrenia, in order to better understand the mechanisms related to social knowledge that underpin social stigma of this disorder and the well-being of people with schizophrenia. Further exploration of the relationship that we have observed between the representations that people with schizophrenia project on to French people and their own representations of schizophrenia would be interesting. For instance, the reproduction of this research in other cultural settings or investigation of representations that people with schizophrenia project on to other groups such as mental health professionals or their family members seem like interesting perspectives. Finally, quasi-experimental studies could enable us to make a more precise analysis of stigmatizing attitudes and behaviors, in relation to the representations that the public may have about schizophrenia and the representations that they attribute to members of their group.

Given all the above-mentioned results of our exploratory study, we consider that in France, as international research also suggests, a name change for schizophrenia seems to be a rather pertinent first solution in the fight against stigma. The term "schizophrenia" is accompanied by very negative images, which go far beyond the psychiatric sense of the word and erasing this word from the professional vocabulary would automatically mean erasing part of the negative content that accompanies it in the minds of both the public and people with schizophrenia. Of course, as Corrigan has claimed, "erasing stigma is much more than changing words" and the contributing factors and underlying mechanisms of the complex stigma phenomenon need to keep being studied. One should not forget either, that as Corrigan suggests, people directly concerned should take the principal role in the fight against stigma. 
This however does not exclude initiatives organized on a structural level for the fight against stigma. As we have already argued, research and broader focus on stigma is a rather recent phenomenon in France, a country that has not participated in global anti-stigma initiatives such as the Time to Change campaign in the UK, the One of Us campaign in Denmark or the Spanish Obertament campaign. Campaigns that target recognition of the suffering and stigma that people with schizophrenia face and that deconstruct stereotypes related to dangerousness and split personality, or even the monitoring of the mediatic use of schizophrenia would prove very useful in the French context.

Further research of this type could lead to perspectives for supporting people living with schizophrenia. For example, diagnostic tools ad hoc to the representational context of these people could be constructed to identify and work more effectively on the effects of social disqualification. An intervention focused on the socio-cognitive remediation of disqualifying social images of schizophrenia could then constitute a relevant therapeutic device to help those most affected by these images. For instance, Yanos, Roe and Lysaker (Yanos et al., 2011) recently developed a cognitive-behavioral therapy to treat internalization of stigma and the effects of social stigmatization on people with schizophrenia. Specifically, this therapy consists of helping people with schizophrenia to work on these dysfunctional beliefs that hinder the development of a positive social identity (Roe et al., 2014). When used in conjunction with the social representations approach, this type of therapy would make it possible to work to improve the self-esteem of people with schizophrenia and to strengthen their capacity to act in the face of stigmatization.

\section{Acknowledgements}

This work was supported by the region of Provence-Alpes-Côte d'Azur (France). 


\section{Conflict of interest}

On behalf of all authors, the corresponding author states that there is no conflict of interest. 


\section{References}

Abdullah, T., Brown, T.L., 2011. Mental illness stigma and ethnocultural beliefs, values, and norms: An integrative review. Clin. Psychol. Rev. 31, 934-948. https://doi.org/10.1016/j.cpr.2011.05.003

Acosta, F.J., Aguilar, E.J., Cejas, M.R., Gracia, R., 2013. Beliefs about illness and their relationship with hopelessness, depression, insight and suicide attempts in schizophrenia. Psychiatr. Danub. 25, 49-54.

Angermeyer, M.C., Carta, M.G., Matschinger, H., Millier, A., Refai, T., Schomerus, G., Toumi, M., 2016. Cultural differences in stigma surrounding schizophrenia: comparison between Central Europe and North Africa. Br. J. Psychiatry 208, 389-397. https://doi.org/10.1192/bjp.bp.114.154260

Angermeyer, M.C., Millier, A., Rémuzat, C., Refaï, T., Toumi, M., 2013. Attitudes and beliefs of the French public about schizophrenia and major depression: results from a vignette-based population survey. BMC Psychiatry 13. https://doi.org/10.1186/1471$244 \mathrm{X}-13-313$

Choe, J.Y., Teplin, L.A., Abram, K.M., 2008. Perpetration of Violence, Violent Victimization, and Severe Mental Illness: Balancing Public Health Concerns. Psychiatr. Serv. 59, 153-164. https://doi.org/10.1176/ps.2008.59.2.153

Corrigan, P.W., 1998. The impact of stigma on severe mental illness. Cogn. Behav. Pract. 5, 201-222. https://doi.org/10.1016/S1077-7229(98)80006-0

Corrigan, P.W., Kerr, A., Knudsen, L., 2005. The stigma of mental illness: Explanatory models and methods for change. Appl. Prev. Psychol. 11, 179-190. https://doi.org/10.1016/j.appsy.2005.07.001 
Dany, L., Urdapilleta, I., Lo Monaco, G., 2015. Free associations and social representations: some reflections on rank-frequency and importance-frequency methods. Qual. Quant. 49, 489-507. https://doi.org/10.1007/s11135-014-0005-z

Denzin, N.K., 2009. The research act: a theoretical introduction to sociological methods. AldineTransaction, New Brunswick, NJ.

Dl Giacomo, J.-P., 1980. Intergroup alliances and rejections within a protest movement (analysis of the social representations). Eur. J. Soc. Psychol. 10, 329-344. https://doi.org/10.1002/ejsp.2420100402

Duckworth, K., Halpern, J.H., Schutt, R.K., Gillespie, C., 2003. Use of Schizophrenia as a Metaphor in U.S. Newspapers. Psychiatr. Serv. 54, 1402-1404. https://doi.org/10.1176/appi.ps.54.10.1402

Durand-Zaleski, I., Scott, J., Rouillon, F., Leboyer, M., 2012. A first national survey of knowledge, attitudes and behaviours towards schizophrenia, bipolar disorders and autism in France. BMC Psychiatry 12. https://doi.org/10.1186/1471-244X-12-128

Evans-Lacko, S., Brohan, E., Mojtabai, R., Thornicroft, G., 2012. Association between public views of mental illness and self-stigma among individuals with mental illness in 14 European countries. Psychol. Med. 42, 1741-1752. https://doi.org/10.1017/S0033291711002558

Farr, R.M., Moscovici, S. (Eds.), 1984. Social representations, European studies in social psychology. Cambridge University Press; Editions de la Maison des Sciences de l’Homme, Cambridge [Cambridgeshire]; New York : Paris.

Fazel, S., Gulati, G., Linsell, L., Geddes, J.R., Grann, M., 2009. Schizophrenia and Violence: Systematic Review and Meta-Analysis. PLoS Med. 6, e1000120. https://doi.org/10.1371/journal.pmed.1000120 
Flament, C., 1981. L'analyse de similitude: une technique pour les recherches sur les représentations sociales. Cah. Psychol. Cogn. Psychol. Cogn. 1, 375-395.

Flament, C., Guimelli, C., Abric, J.-C., 2006. Effets de masquage dans l'expression d'une représentation sociale. Cah. Int. Psychol. Soc. 1, 15-31.

Flament, C., Milland, L., 2010. La substitution dans les études de représentations sociales: quel processus impliqué ? Psychol. Fr. 55, 195-210. https://doi.org/10.1016/j.psfr.2010.05.003

Fung, K.M.T., Tsang, H.W.H., Corrigan, P.W., 2008. Self-stigma of people with schizophrenia as predictor of their adherence to psychosocial treatment. Psychiatr. Rehabil. J. 32, 95-104. https://doi.org/10.2975/32.2.2008.95.104

Goffman, E., 1963. Stigma: notes on the management of spoiled identity. Simon \& Schuster, New York.

Guimelli, C., Deschamps, J.-C., 2000. Context effects on verbal association production: Social representations of Gypsies. Cah. Int. Psychol. Soc. 47, 44-54.

Guimelli, C., Lo Monaco, G., Deschamps, J.-C., 2010. The lawsuit against "Charlie Hebdo" and its effects on the social representations of the Muslim Community. Rev. Int. Psychol. Soc. 4, 5-36.

Jodelet, D., 2003. 1. Représentations sociales: un domaine en expansion, in: Les représentations sociales. Presses Universitaires de France, p. 45. https://doi.org/10.3917/puf.jodel.2003.01.0045

Jung, Y., Pawlowski, S.D., 2014. Understanding consumption in social virtual worlds: A sensemaking perspective on the consumption of virtual goods. J. Bus. Res. 67, 22312238. https://doi.org/10.1016/j.jbusres.2014.01.002

Lafocarde, M., 2016. Rapport relatif à la santé mentale. Ministère des affaires sociales et de la santé, France. 
Lampropoulos, D., Apostolidis, T., 2018. Social Dominance Orientation and Discrimination against People with Schizophrenia: Evidence of Medicalization and Dangerousness Beliefs as Legitimizing Myths. Span. J. Psychol. 21. https://doi.org/10.1017/sjp.2018.46

Lampropoulos, D., Fonte, D., Apostolidis, T., 2018. La stigmatisation sociale des personnes vivant avec la schizophrénie: une revue systématique de la littérature. LÉvolution Psychiatr. https://doi.org/10.1016/j.evopsy.2018.09.002

Lampropoulos, D., Wolman, A., Apostolidis, T., 2017. Analyzing the presentation and the stigma of schizophrenia in French newspapers. Soc. Psychiatry Psychiatr. Epidemiol. 52, 1541-1547. https://doi.org/10.1007/s00127-017-1455-0

Link, B.G., 1987. Understanding Labeling Effects in the Area of Mental Disorders: An Assessment of the Effects of Expectations of Rejection. Am. Sociol. Rev. 52, 96. https://doi.org/10.2307/2095395

Link, B.G., Cullen, F.T., Frank, J., Wozniak, J.F., 1987. The Social Rejection of Former Mental Patients: Understanding Why Labels Matter. Am. J. Sociol. 92, 1461-1500. https://doi.org/10.1086/228672

Link, B.G., Phelan, J.C., 2013. Labeling and stigma, in: Handbook of the Sociology of Mental Health. Springer Netherlands, Dordrecht, pp. 525-541.

Lo Monaco, G., Piermattéo, A., Rateau, P., Tavani, J.L., 2017. Methods for Studying the Structure of Social Representations: A Critical Review and Agenda for Future Research: Methods and Structure of Social Representations. J. Theory Soc. Behav. 47, 306-331. https://doi.org/10.1111/jtsb.12124

Maia, V.L.L.B., Lago, E.C., Ramos, C.V., Fernandes, M.A., Alves, E.L.M., Batista, P.M.S., Maia, R.B., Moura, M.E.B., Moura, L.K.B., Cronemberger, G.L., 2017. Similarity 
Analysis About The Training Of Family Health Strategy Professionals For The Psychosocial Care Of The Elderly. Int. Arch. Med. 10. https://doi.org/10.3823/2501

Mak, W.W.S., Poon, C.Y.M., Pun, L.Y.K., Cheung, S.F., 2007. Meta-analysis of stigma and mental health. Soc. Sci. Med. 65, 245-261. https://doi.org/10.1016/j.socscimed.2007.03.015

Marková, I., 2005. Dialogicality and social representations: the dynamics of mind, Paperback version. ed. Cambridge Univ. Press, Cambridge.

Ministère du travail, de l'emploi et de la santé, 2011. Plan psychiatrie et santé mentale 20112015. Ministère du travail, de l'emploi et de la santé, France.

Read, J., Haslam, N., Sayce, L., Davies, E., 2006. Prejudice and schizophrenia: a review of the "mental illness is an illness like any other" approach. Acta Psychiatr. Scand. 114, 303-318. https://doi.org/10.1111/j.1600-0447.2006.00824.x

Rebeiro Gruhl, K.L., Kauppi, C., Montgomery, P., James, S., 2012. Painting everybody with the same brush: Employment discrimination of persons with serious mental illness in rural places. J. Rural Ment. Health 36, 11-17. https://doi.org/10.1037/h0094775

Reips, U.-D., 2002. Standards for Internet-Based Experimenting. Exp. Psychol. Former. Z. Für Exp. Psychol. 49, 243-256. https://doi.org/10.1027//1618-3169.49.4.243

Roe, D., Hasson-Ohayon, I., Mashiach-Eizenberg, M., Derhy, O., Lysaker, P.H., Yanos, P.T., 2014. Narrative Enhancement and Cognitive Therapy (NECT) Effectiveness: A QuasiExperimental Study: Narrative Enhancement and Cognitive Therapy (NECT) Effectiveness. J. Clin. Psychol. 70, 303-312. https://doi.org/10.1002/jclp.22050

Schomerus, G., Kenzin, D., Borsche, J., Matschinger, H., Angermeyer, M.C., 2007. The association of schizophrenia with split personality is not an ubiquitous phenomenon: Results from population studies in Russia and Germany. Soc. Psychiatry Psychiatr. Epidemiol. 42, 780-786. https://doi.org/10.1007/s00127-007-0235-7 
Thonon, B., Larøi, F., 2017. What predicts stigmatisation about schizophrenia? Results from a general population survey examining its underlying cognitive, affective and $\begin{array}{llll}\text { behavioural } & \text { factors. } & \text { Psychosis } & 9,\end{array}$ https://doi.org/10.1080/17522439.2016.1229361

WHO, 2013. Mental health action plan 2013-2020. World Health Organization, Geneva.

WHO, 2003. Investing in mental health. World Health Organization, Geneva.

Yang, L.H., Kleinman, A., Link, B.G., Phelan, J.C., Lee, S., Good, B., 2007. Culture and stigma: Adding moral experience to stigma theory. Soc. Sci. Med. 64, 1524-1535. https://doi.org/10.1016/j.socscimed.2006.11.013

Yanos, P.T., Roe, D., Lysaker, P.H., 2011. Narrative Enhancement and Cognitive Therapy: A New Group-Based Treatment for Internalized Stigma Among Persons with Severe Mental Illness. Int. J. Group Psychother. 61, 576-595. https://doi.org/10.1521/ijgp.2011.61.4.576

Yanos, P.T., Roe, D., Markus, K., Lysaker, P.H., 2008. Pathways Between Internalized Stigma and Outcomes Related to Recovery in Schizophrenia Spectrum Disorders. Psychiatr. Serv. 59, 1437-1442. https://doi.org/10.1176/ps.2008.59.12.1437 
Table 1. Socio-demographic characteristics of participants.

\begin{tabular}{lll}
\hline Variable & Participants & \\
\cline { 2 - 3 } & Without schizophrenia & With schizophrenia \\
$N=98$ & $N=59$ \\
\hline$n(\%)$ & & $n(\%)$
\end{tabular}

Gender

$\begin{array}{lll}\text { Male } & 49(50.0) & 24(40.7) \\ \text { Female } & 46(46.9) & 35(59.3) \\ \text { Other } & 3(3.1) & 0(0)\end{array}$

Age (years)

$\begin{array}{lll}18-39 & 52(53.1) & 36(61.0) \\ 40-59 & 33(33.7) & 18(30.5) \\ 60 \text { and more } & 11(11.2) & 5(8.5)\end{array}$

Education
$<$ H. S.
15 (15.3)
$16(27.1)$
H. S. graduate
37 (37.8)
34 (57.6)
$>=$ Bachelor
$44(44.9)$
9 (15.3)

Occupation

$\begin{array}{lll}\text { Yes } & 84(85.7) & 22(37.3) \\ \text { No } & 12(12.2) & 37(62.7)\end{array}$


Table 2. Cognitive content from prototypic analysis.

\section{Participants}

\begin{tabular}{|c|c|c|c|}
\hline \multicolumn{2}{|l|}{ Without schizophrenia } & \multicolumn{2}{|l|}{ With schizophrenia } \\
\hline$N=98$ & & $N=59$ & \\
\hline For themselves & For others & For themselves & For others \\
\hline Illness $(38 / 2.0)$ & Madness (60/1.7) & Delirium (14/2.0) & Madness (41/2.0) \\
\hline Madness $(32 / 2.1)$ & Illness $(32 / 2.1)$ & Hallucination $(13 / 2.5)$ & Danger (27/2.3) \\
\hline Split personality $(22 / 2.4)$ & Mental illness (17/1.7) & Illness (13/1.9) & Illness $(18 / 2.2)$ \\
\hline Mental illness (15/1.8) & Split personality $(15 / 2.2)$ & Madness (11/2.6) & Killer (17/2.5) \\
\hline Treatment (11/3.9) & Danger $(15 / 2.8)$ & Voices $(14 / 3.0)$ & Abnormal (11/2.5) \\
\hline Hospital (8/3.6) & Confinement (11/3.5) & Suffering $(13 / 2.8)$ & Split personality $(8 / 3.0)$ \\
\hline $\operatorname{Sad}(7 / 3.7)$ & Fear (10/2.6) & Isolation (10/3.4) & Dumb (7/3.0) \\
\hline Hallucination (7/3.3) & Hospital (10/3.9) & Paranoia $(7 / 2.4)$ & Psychiatry (7/3.9) \\
\hline Fear $(6 / 2.8)$ & Treatment $(8 / 3.9)$ & Depression $(6 / 2.5)$ & Voices $(7 / 3.3)$ \\
\hline Danger (6/4.0) & Prejudice (7/2.4) & Anxiety $(7 / 4.1)$ & Confinement (7/4.3) \\
\hline Bipolar (6/2.7) & Bipolar (7/3.0) & Fear $(5 / 3.0)$ & Hospital (6/3.3) \\
\hline Care (6/3.0) & Psychopath (6/3.2) & Loneliness (5/3.4) & Violence $(5 / 3.4)$ \\
\hline Confinement (5/3.4) & Disorder $(5 / 2)$ & Visions (5/4.2) & Psychopath (5/2.8) \\
\hline & Weird $(5 / 3.4)$ & & Fear $(6 / 2.2)$ \\
\hline
\end{tabular}

Note. Words are presented in descending order according to their salience (frequency x rank). The first number in brackets represents the frequency of the words elicited, while the second number represents the mean rank of appearance. 
Figure 1. Relations between cognitive content generated by the similarity analysis for participants without schizophrenia $(N=98)$.

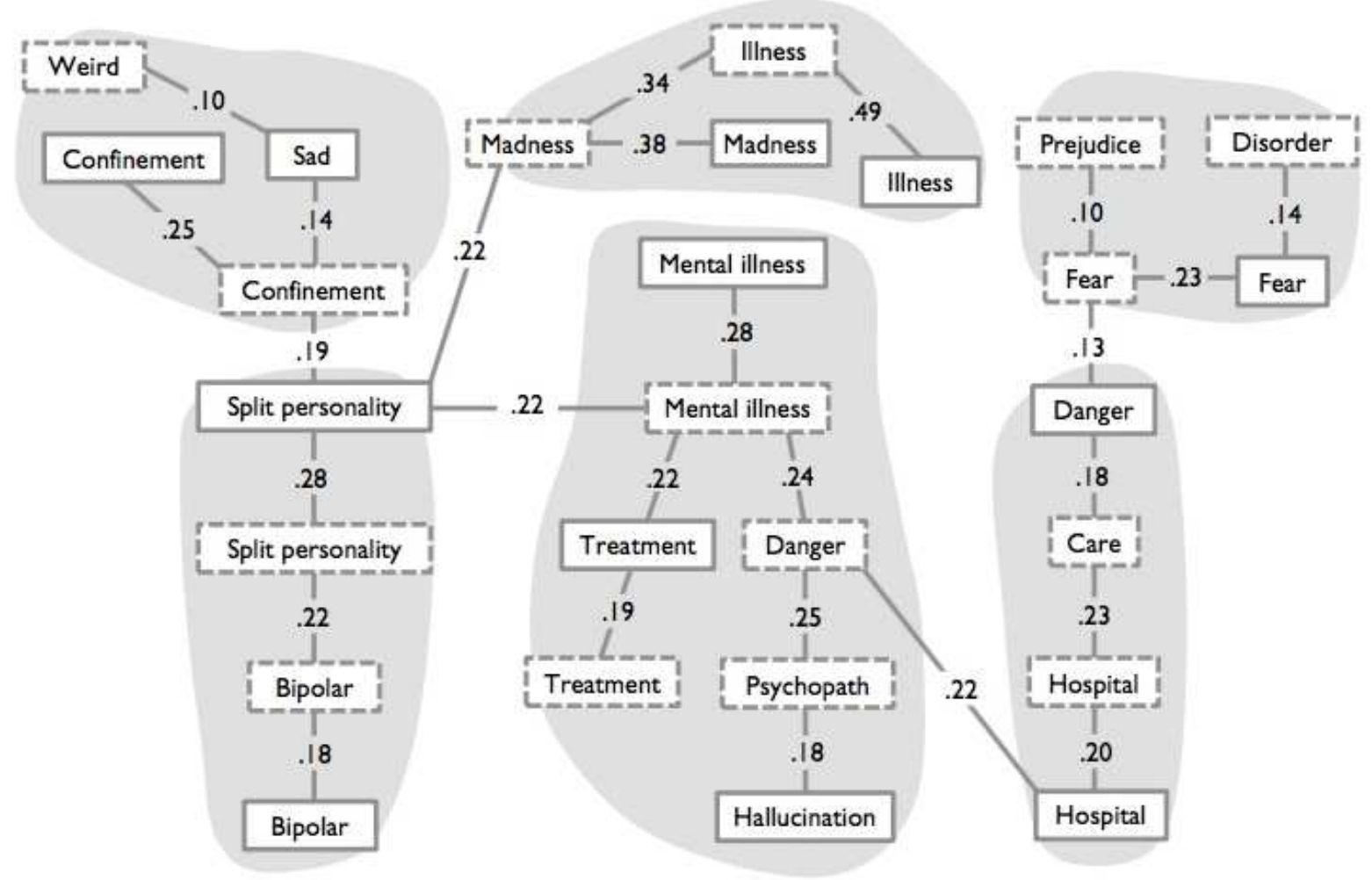

Note. Boxes with unbroken lines represent the responses of participants on their own behalf. The boxes with dotted lines represent the responses they attribute to others. Numbers represent proximity relations according to the Jaccard index. Grey halos represent the communities of words according to this index. 
Figure 2. Relations between cognitive content generated by the similarity analysis for participants with schizophrenia $(N=59)$.

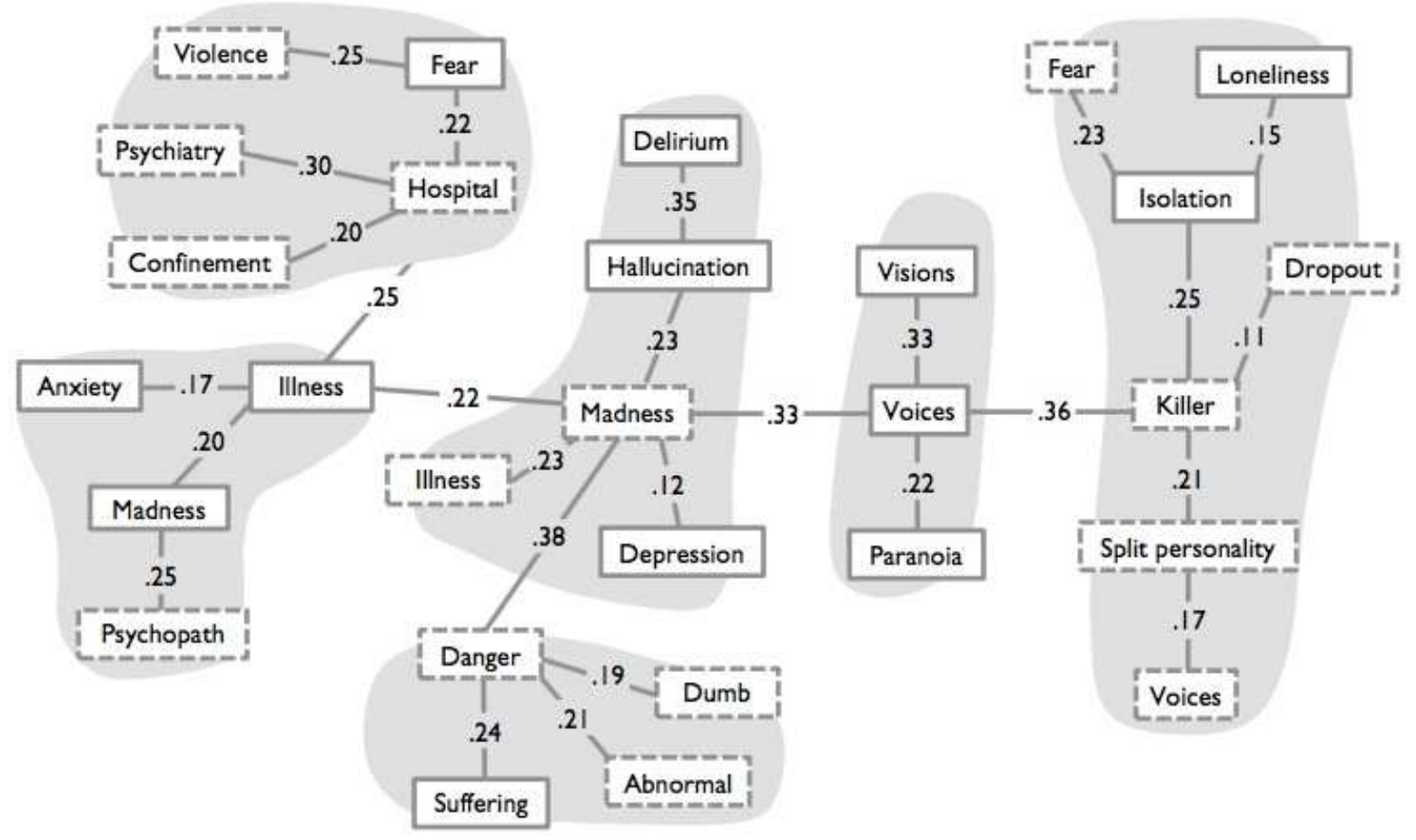

Note. Boxes with unbroken lines represent the responses of participants on their own behalf. The boxes with dotted lines represent the responses they attribute to others. Numbers represent proximity relations according to the Jaccard index. Grey halos represent the communities of words according to this index. 